\title{
Monitoring and Assessment of Wetlands: Concepts, case Studies, and Lessons Learned
}

\section{Denice H. Wardrop, Mary E. Kentula, Robert P. Brooks, M. Siobhan Fennessy, Sarah J. Chamberlain,}

Kirk J. Havens, Carl Hershner

\section{Chapter 11 - abstract}

Monitoring and assessment (M\&A) have long been considered critical components of any resource management program where there is a need to evaluate progress and performance over time.

Understanding the origins of current monitoring and assessment strategies and techniques for wetlands in the U.S. provides useful perspectives on how wetlands are both similar and different from other waters and allows us to take advantage of the lessons learned across all aquatic resources. We highlight several knowledge threads that significantly influenced how we approach M\&A today, including legal mandates, tools developed to improve the management of resources, and scientific evidence of the utility of M\&A information. We describe the role of regional forums in the evolution and development of these tools and in the building of support for their programmatic integration in the Mid-Atlantic Region (MAR). We then tell the story of their use and application at a variety of spatial scales, including site-level mitigation applications in Pennsylvania, watershed application in the Upper Juniata Watershed, regional application in the MAR, and, finally, national application in the National Wetland Condition Assessment. We document the lessons learned, and present an example of promising future use of M\&A data in the construction of Tiered Aquatic Life Use Standards for wetlands. 